\title{
Inhibition of EGFR autophosphorylation plays an important role in the anti-breast cancer efficacy of the dithiocarbamate derivative TM208
}

\author{
Xi-wei $\mathrm{JI}^{2}$, Run-tao $\mathrm{LI}^{1}$, Zai-quan $\mathrm{LI}^{3}$, Liang $\mathrm{LI}^{2}$, Xue-yan $\mathrm{SHAO}^{2}$, Si-yuan WANG ${ }^{2}$, Yin YUAN², Tian-yan ZHOU1, 2, *, \\ Wei $\mathrm{LU}^{1,2, *}$

\begin{abstract}
${ }^{1}$ State Key Laboratory of Natural and Biomimetic Drugs, School of Pharmaceutical Sciences, Peking University, Beijing 100191, China; ${ }^{2}$ Department of Pharmaceutics, School of Pharmaceutical sciences, Peking University, Beijing 100191, China; ${ }^{3}$ Department of Radia-
\end{abstract} \\ tion Medicine, Peking University, Beijing 100191, China
}

Aim: To investigate the effects of a novel dithiocarbamate derivative TM208 on human breast cancer cells as well as the pharmacokinetic characteristics of TM208 in human breast cancer xenograft mice.

Methods: Human breast cancer MCF-7 and MDA-MB-231 cells were treated with TM208 or a positive control drug tamoxifen. Cell proliferation was examined using SRB and colony formation assays. Cell apoptosis was analyzed with Annexin V-FITC/PI staining assay. Protein expression was examined with Western blot, ELISA and immunohistochemical analyses. MCF-7 breast cancer xenograft nude mice were orally administered TM208 (50 or $150 \mathrm{mg} \cdot \mathrm{kg}^{-1} \cdot \mathrm{d}^{-1}$ ) or tamoxifen $\left(50 \mathrm{mg} \cdot \mathrm{kg}^{-1} \cdot \mathrm{d}^{-1}\right)$ for $18 \mathrm{~d}$. On d 19 , the tumors were collected for analyses. Blood samples were collected from the mice treated with the high dose of TM208, and plasma concentrations of TM208 were measured using LC-MS/MS.

Results: Treatment of MCF-7 and MDA-MB-231 cells with TM208 dose-dependently inhibited the cell proliferation and colony formation in vitro (the $\mathrm{IC}_{50}$ values were $36.38 \pm 3.77$ and $18.13 \pm 0.76 \mu \mathrm{mol} / \mathrm{L}$, respectively). TM208 (20-150 $\left.\mu \mathrm{mol} / \mathrm{L}\right)$ dose-dependently induced apoptosis of both the breast cancer cells in vitro. In MCF-7 breast cancer xenograft nude mice, TM208 administration dose-dependently reduced the tumor growth, but did not result in the accumulation of TM208 or weight loss. TM208 dose-dependently inhibited the phosphorylation of EGFR and ERK1/2 in both the breast cancer cells in vitro as well as in the MCF-7 xenograft tumor.

Conclusion: Inhibition of EGFR autophosphorylation plays an important role in the anticancer effect of TM208 against human breast cancer.

Keywords: breast cancer; dithiocarbamate; TM208; tyrosine kinase inhibitor; EGFR; ERK1/2; phosphorylation; tumor xenograft nude mice

Acta Pharmacologica Sinica (2014) 35: 239-247; doi: 10.1038/aps.2013.156; published online 30 Dec 2013

\section{Introduction}

The epidermal growth factor receptor (EGFR) is a member of the ErbB receptor family of tyrosine kinases (TKs) that is overexpressed in a variety of human solid tumors, such as breast cancer and non-small cell lung cancer ${ }^{[1,2]}$. When bound to its ligand (either epidermal growth factor or transforming growth factor $\alpha$ ), the kinase domain is activated and generates phosphorylated EGFR (p-EGFR), which results in a signaling cascade that produces diverse effects, such as cell migration, maturation and inhibition of apoptosis ${ }^{[3]}$. Deregulation of

\footnotetext{
* To whom correspondence should be addressed.

E-mail luwei_pk@bjmu.edu.cn (Wei LU); tianyanzhou@bjmu.edu.cn (Tian-yan ZHOU)

Received 2013-06-03 Accepted 2013-09-23
}

EGFR expression and signaling is well documented and has been shown to contribute to disease recurrence and metastasis in many types of cancer, including breast cancer ${ }^{[4,5]}$.

The Ras-Raf-MAPK (mitogen-activated protein kinase) pathway is one of the major downstream signaling routes of the ErbB/HER (human epidermal growth factor receptor) family $^{[6]}$. Following EGFR activation and consecutive TK phosphorylation, the downstream MAPK pathway is activated ${ }^{[7]}$, leading to the induction of cell proliferation and migration ${ }^{[8]}$. Trastuzumab, a humanized monoclonal antibody of HER2, and lapatinib, a small molecular inhibitor of EGFR, have been approved by the FDA for the treatment of HER2-overexpressing breast cancers ${ }^{[9]}$. Some published data also show that EGFR signaling is required for the self-renewal of cancer cells in mammospheres ${ }^{[10]}$, and treatment with lapatinib decreases 
the percentage of chemotherapy-resistant CD $44^{+} / \mathrm{CD} 24^{-/ \text {low }}$ tumorigenic stem cells in breast cancer patients ${ }^{[11]}$, suggesting that the inhibition of the EGFR pathway may provide a therapeutic strategy for eliminating these breast cancer stem cells, thus decreasing the recurrence and improving long-term survival.

Dithiocarbamates, a type of fungicide, are widely used in agriculture due to their low price and effectiveness. Dithiocarbamates have antibiotic and anti-inflammatory properties and can remove nitrogen monoxide from the body, as well as chelate heavy metals in the body ${ }^{[12-15]}$. Additionally, dithiocarbamates can be used to prevent or treat cancer ${ }^{[16,17]}$. Recently, a series of new dithiocarbamate derivatives was synthesized ${ }^{[18-20]}$, including 4-methyl-piperazine-1-carbodithioc acid 3-cyano-3,3-diphenylpropyl ester hydrochloride (TM208, Figure 1). Results from previous studies indicated that TM208 can significantly inhibit the growth of transplanted hepatocellular carcinomas and gastric carcinomas in nude mice with low toxicity, possibly by inhibiting the Ras-Raf-MAPK pathway $^{[21,22]}$. However, the effect of TM208 on EGFR signaling was not investigated in previous studies. Additionally, the anti-breast cancer effect of TM208, as well as its corresponding mechanism of the inhibition, have not yet been studied in breast cancer.

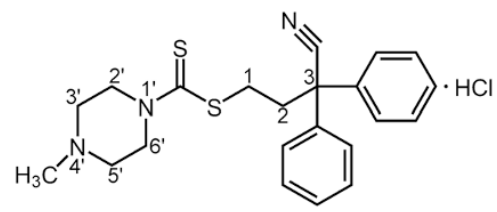

Figure 1. The chemical structure of TM208.

The purpose of this study was to investigate the inhibition of TM208 on breast cancer cells in vitro and in vivo, and more importantly, to achieve a better understanding of the potential role of p-EGFR inhibition in breast cancer treatment using TM208. To accomplish this, we first examined the effects of TM208 on cell proliferation and apoptosis in the MCF-7 and MDA-MB-231 cell lines in vitro. We then evaluated its antitumor effects in MCF-7 xenograft tumors in vivo. Lastly, we investigated the effects of TM208 on EGFR/ERK1/2 signaling in both the breast cancer cell lines and the xenograft tumors. Tamoxifen (Tam) was used as a positive control to measure the anti-breast cancer effects of TM208 in vitro and in vivo.

\section{Materials and methods Drugs and reagents}

TM208 (>99.5\%) was provided by Prof Run-tao LI (Peking University) ${ }^{[23]}$. Tam was purchased from Lanospharma Laboratories Co Ltd (Chongqing, China). Sulforhodamine B (SRB) was obtained from Sigma-Aldrich (Sheboygan, WI, USA). RPMI-1640 and DMEM media were obtained from Macgene Biotech Co, Ltd (Beijing, China), and fetal bovine serum (FBS) was purchased from Gibco (Grand Island, NY, USA). Primary antibodies against phospho-EGFR (Try1068), EGFR, phosphop44/42 MAPK (p-ERK1/2) and p44/42 MAPK (ERK1/2) and horseradish peroxidase-conjugated anti-mouse secondary antibodies were obtained from Cell Signaling Technology (Danvers, MA, USA).

\section{Cell culture}

The MCF-7 cell line was provided by Prof Wan-liang LU (Peking University). The MDA-MB-231 cell line was obtained from the Cell Bank of the Cancer Institute and Hospital, Chinese Academy of Medical Science. MCF-7 and MDA-MB-231 cells were cultured in RPMI-1640 and DMEM medium, respectively, supplemented with $10 \%$ FBS, $100 \mathrm{U} / \mathrm{mL}$ penicillin and $100 \mu \mathrm{g} / \mathrm{mL}$ streptomycin. All cells were maintained at $37^{\circ} \mathrm{C}$ in a $5 \% \mathrm{CO}_{2}$ atmosphere.

\section{Animals}

The female BALB/c nude mice (5-6 weeks old) were provided by Beijing Vital Laboratory Animal Technology (Beijing, China). Animal procedures were approved by the Department of Laboratory Animal Science of Peking University Health Science Center (Beijing, China). The nude mice were housed under standard temperature $\left(25-28^{\circ} \mathrm{C}\right)$, humidity $(50 \%-60 \%)$ and light (12 h light/12 h dark) conditions with free access to food and water before being used in this study.

\section{Cell proliferation and viability assays in vitro}

The inhibition of proliferation was evaluated using the SRB colorimetric assay in the breast cancer cell lines. Briefly, MCF-7, and MDA-MB-231 cells in the exponential growth phase were seeded in 96-well microplates at a density of $1 \times 10^{4}$ cells/well. After $24 \mathrm{~h}$ of incubation to allow for sufficient cell adhesion, the cells were treated for $48 \mathrm{~h}$ with TM208 (0.2-150 $\mu \mathrm{mol} / \mathrm{L})$ or Tam $(0.2-100 \mu \mathrm{mol} / \mathrm{L})$ in 6 replicate wells for each drug concentration. DMSO was used as a vehicle control. After treatment for $48 \mathrm{~h}$, the cells were then fixed with cold $10 \%(w / v)$ trichloroacetic acid at $4^{\circ} \mathrm{C}$ for $1 \mathrm{~h}$. The plates were then washed with tap water, stained with $0.4 \%$ SRB $(w / v$, in $1 \%$ acetic acid), and washed with $1 \%$ acetic acid. The proteinbound dye was subsequently dissolved in $10 \mathrm{mmol} / \mathrm{L}$ Tris, and the absorbance was read at $540 \mathrm{~nm}$ on an IMAK microplate reader (Bio-Rad Laboratories, Hercules, CA, USA). The final DMSO concentration in each well was less than $1 \%(v / v)$. The growth inhibitory $\mathrm{IC}_{50}$ values for TM208 in the two cell lines were determined according to a published protocol ${ }^{[24]}$. The percentage of cell survival was calculated using the formula: Percentage of cell survival $=O D_{\text {treated }} / O D_{\text {control }} \times 100 \%$.

\section{Colony formation assay}

MCF-7 and MDA-MB-231 cells were seeded in 10-cm dishes at a density of $1 \times 10^{4}$ cells/plate. From d 2 to $d 8$, the medium was changed daily, and the cells were treated with TM208 at concentrations of $0,20,50$, or $150 \mu \mathrm{mol} / \mathrm{L}$. The cultures were then fixed with methanol and stained with $0.5 \%$ w/v crystal violet dissolved in $25 \%$ methanol. Colonies were defined by clumps that consisted of more than 50 cells. 


\section{Cell apoptosis detection}

MCF-7 and MDA-MB-231 cells were seeded in 25- $\mathrm{cm}^{2}$ culture flasks at a density of $3 \times 10^{5}$ cells/flask. After incubation with different concentrations of TM208 $(20,50$, or $150 \mu \mathrm{mol} / \mathrm{L})$ for $24 \mathrm{~h}$, the cells were washed twice with cold PBS. The cells were collected by centrifugation at $2000 \mathrm{r} / \mathrm{min}$ for $5 \mathrm{~min}$ and were resuspended in $1 \times$ binding buffer; $5 \mu \mathrm{L}$ of Annexin $\mathrm{V}$-FITC and $5 \mu \mathrm{L}$ of propidium iodide (PI) staining solution (BD Pharmingen, San Diego, CA, USA) were added into a 5-mL culture tube containing $100 \mu \mathrm{L}$ of the cell suspension, followed by incubation for $15 \mathrm{~min}$ in the dark at room temperature $\left(25^{\circ} \mathrm{C}\right)$. Finally, the cells were suspended in $400 \mu \mathrm{L}$ $1 \times$ binding buffer and were analyzed within $1 \mathrm{~h}$ using a FACSCalibur flow cytometer (Becton-Dickinson, San Jose, CA, USA).

\section{Tumor xenograft model}

MCF-7 cells $\left(2 \times 10^{6}\right)$ were suspended in $200 \mu \mathrm{L}$ of PBS ( $\mathrm{pH}$ $7.4)$ and were inoculated subcutaneously into the second mammary fat pads of the nude mice. The tumor diameter was measured using vernier calipers and was converted to tumor volume using the formula $1 / 2 \times A \times B^{2}$, where $A$ is the larger diameter, and $B$ is the smaller diameter. Treatment was started when the average tumor volume reached $150 \mathrm{~mm}^{3}$.

\section{Tumor growth inhibition assay}

Xenograft mice were randomly divided into five groups with four mice in each group. TM208 was dissolved in 15\% hydroxypropyl- $\beta$-cyclodextrin aqueous solution and was administered by intragastric gavage at a dosage of 50 or 150 $\mathrm{mg} \cdot \mathrm{kg}^{-1} \cdot \mathrm{d}^{-1}$. The blank control group received only the vehicle solution, whereas the positive control group received 50 $\mathrm{mg} \cdot \mathrm{kg}^{-1} \cdot \mathrm{d}^{-1}$ Tam. Tumor size and body weight were measured every three days. After $18 \mathrm{~d}$ of treatment, the animals were euthanized by cervical displacement. The tumors were collected after the final treatment and were frozen at $-80^{\circ} \mathrm{C}$ until use.

\section{Pharmacokinetic study}

Tumor-bearing nude mice received intragastric administration of TM208 at $150 \mathrm{mg} / \mathrm{kg}$ at 9:00 AM daily, and blood samples were obtained at $0,0.5,1,4,10,24,36,48,120,192$, $264,336,408,409,418$, and $432 \mathrm{~h}$ from three mice at each time point. The serum concentrations of TM208 were determined using the previously established LC-MS/MS method ${ }^{[25]}$. Data processing was performed with DAS software (version 2.1.1, Drug and Statistics, Mathematical Pharmacology Professional Committee of China, Shanghai, China).

\section{Western blot analysis}

To investigate the effect of TM208 on EGFR/ERK1/2 signaling pathway in vitro, the MDA-MB-231 and MCF-7 cells were incubated with $20 \mu \mathrm{mol} / \mathrm{L}$ and $50 \mu \mathrm{mol} / \mathrm{L}$ TM208, respectively, or the vehicle control for $2 \mathrm{~h}$. The cells were then harvested using $0.25 \%$ trypsin-EDTA solution (Sigma-Aldrich, St Louis, MO, USA), washed with PBS ( $\mathrm{pH} 7.4$ ), and homogenized in ice-cold RIPA cell lysis buffer $(50 \mathrm{mmol} / \mathrm{L}$ Tris, $\mathrm{pH} 7.4,150$ $\mathrm{mmol} / \mathrm{L} \mathrm{NaCl}, 1 \% \mathrm{NP}-40,0.5 \%$ sodium deoxycholate, $0.1 \%$ SDS, protease inhibitor and $1 \mathrm{mmol} / \mathrm{L}$ phenylmethanesulfonyl fluoride). The homogenates were then centrifuged at $12000 \times g$ for $30 \mathrm{~min}$; the supernatants were collected, and their protein concentrations were determined with a BCA protein assay kit (Beyotime Biotechnology, Haimen, China).

The tumor-bearing mice were treated with 50 or 150 $\mathrm{mg} \cdot \mathrm{kg}^{-1} \cdot \mathrm{d}^{-1} \mathrm{TM} 208$ for $18 \mathrm{~d}$. On $\mathrm{d} 19$, the tumors were collected and were homogenized in $50 \mathrm{mmol} / \mathrm{L}$ Tris buffer $(\mathrm{pH} 7.4)$ containing $0.25 \mathrm{~mol} / \mathrm{L}$ sucrose, $3 \mathrm{mmol} / \mathrm{L} \beta$-mercaptoethanol and $0.02 \%(v / v)$ Tween-20. All homogenates were centrifuged at $40000 \times \mathrm{g}$ for $1 \mathrm{~h}$ at $4^{\circ} \mathrm{C}$, and the protein concentrations of the cytosol were determined using the BCA protein assay kit used above. Cytosol aliquots were collected and stored at $-80^{\circ} \mathrm{C}$. For each treatment group, an equal amount of cytosolic protein from each tumor was combined for Western blot analysis.

Total protein $(50 \mu \mathrm{g})$ was separated by $12 \%$ SDS-polyacrylamide gel electrophoresis (SDS-PAGE) and was transferred to PVDF membranes (Pierce, Rockford, IL, USA). The following primary antibodies were used: p-EGFR (1:500), EGFR (1:1500), p-ERK (1:2000), and ERK (1:2000). A horseradish peroxidaseconjugated anti-mouse antibody $(1: 6000)$ was used as a secondary antibody. The membrane was developed using the Supersignal Ultra reagents (Pierce, Rockford, IL, USA). The densitometric quantification of the protein bands was determined using the ChemiDoc XRS+System (Bio-Rad Laboratories, Hercules, CA, USA). Three animals were used for each treatment group, and each experiment was repeated three times.

\section{Quantitative measurement of p-EGFR in the tumor samples}

Xenograft mice were randomly divided into three groups: the vehicle-control group, the single-dose group and the continuous-dose group. For the single dose group, nude mice received a single administration of $150 \mathrm{mg} / \mathrm{kg}$ TM208 when the average tumor size reached $50 \mathrm{~mm}^{3}$, and the tumors were collected before administration $(0 \mathrm{~h})$ and at 1,10 , and $24 \mathrm{~h}$ after dosing; 3 mice were examined at each time point. Alternatively, the tumor-bearing mice of the other two groups were treated with the vehicle solution or $150 \mathrm{mg} \cdot \mathrm{kg}^{-1} \cdot \mathrm{d}^{-1} \mathrm{TM} 208$. The tumors were collected at $0,3,6,9$, and $12 \mathrm{~d}$, and 3 mice were examined at each time point for each group. These tumors were washed in ice-cold saline and snap-frozen. All tumors were cut into small pieces and sonicated for $25 \mathrm{~s}$ in ice-cold PBS ( $\mathrm{pH}$ 7.4). The tumor lysates were centrifuged at $12000 \times g$ for $30 \mathrm{~min}$ at $4^{\circ} \mathrm{C}$, and then the supernatants were collected. The concentration of p-EGFR in $100 \mu \mathrm{g}$ of total protein extract was measured using a human p-EGFR ELISA kit (Beijing Puli Zhicheng Biotechnology Co, Ltd, Beijing, China).

\section{Immunohistochemical (IHC) staining}

After the paraffin sections of the tumors were deparaffinized, rehydrated and washed with PBS ( $\mathrm{pH} 7.4$ ), antigen retrieval was performed by boiling the sections in $10 \mathrm{mmol} / \mathrm{L}$ sodium citrate buffer ( $\mathrm{pH}$ 6.0) in a microwave for $4 \mathrm{~min}$. The endog- 
enous peroxidase activity was quenched by placing the slides in 3\% hydrogen peroxide in methanol. The slides were then blocked with 3\% BSA-PBS followed by incubation with a 1:425 dilution of the p-EGFR antibody (Cell Signaling Technology, Danvers, MA, USA) overnight at $4{ }^{\circ} \mathrm{C}$. Thereafter, detection was performed using a biotin-conjugated secondary antibody and a streptavidin-horseradish peroxidase conjugate (SAHRP), followed by colorimetric detection using diaminobenzidine (DAB). The sections were counterstained with hematoxylin and were stabilized with mounting medium.

\section{Statistical analysis}

When applicable, the results are presented as the mean \pm SD. One-way analysis of variance (ANOVA) was used to determine the significance among the groups, and post hoc tests with Bonferroni's correction were used for multiple comparisons among the individual groups. The differences were considered statistically significant when $P<0.05$. Statistical analyses were performed using GraphPad Prism 5.0 software (GraphPad Software Inc, La Jolla, CA, USA).

\section{Results}

\section{Effects of TM208 on cell proliferation and apoptosis}

TM208 inhibited the proliferation of MCF-7 and MDA-MB-231 cells (Figure 2A). The inhibitory effects of TM208 gradually enhanced as the concentration increased, achieving a maximal inhibition of $66 \%$ (MCF-7) and $89 \%$ (MDA-MB-231) at the maximum concentration. The $\mathrm{IC}_{50}$ values of $\mathrm{TM} 208$ in the MCF-7 and MDA-MB-231 cells were 36.38 $\pm 3.77 \mu \mathrm{mol} / \mathrm{L}$ and $18.13 \pm 0.76 \mu \mathrm{mol} / \mathrm{L}$, respectively. In the MCF-7 and MDAMB-231 cells, Tam exhibited a maximum inhibition rate of 97\% and $93 \%$, respectively, with $\mathrm{IC}_{50}$ values of $22.45 \pm 2.36 \mu \mathrm{mol} / \mathrm{L}$ and $5.70 \pm 0.79 \mu \mathrm{mol} / \mathrm{L}$, respectively. Additionally, TM208 showed significant inhibitory effects on colony formation in both cell lines in a dose-dependent pattern (Figure 2B). The number of colonies under the control conditions increased exponentially as a function of time, whereas TM208 caused a complete stagnation in the number of living cells.

Annexin V-FITC/PI double-labeled flow cytometry was used to assess the percentage of apoptotic MCF-7 and MDAMB-231 cells after TM208 treatment (Figure 2C). MCF-7 and MDA-MB-231 cells were treated with 20, 50, or $150 \mu \mathrm{mol} / \mathrm{L}$ TM208 for $24 \mathrm{~h}$. The total apoptotic percentage was the sum of the early apoptotic and late apoptotic percentages. The apoptosis rates for the MCF-7 cells treated with 20, 50, and 150 $\mu \mathrm{mol} / \mathrm{L}$ were $7.60 \% \pm 0.49 \%, 19.22 \% \pm 1.00 \%$, and $25.69 \% \pm 0.86 \%$, respectively, which were significantly higher than that of the vehicle control group $(5.91 \% \pm 0.28 \%)$. The apoptosis rates for the MDA-MB-231 cells treated with 20, 50, and $150 \mu \mathrm{mol} / \mathrm{L}$ were $24.42 \% \pm 3.07 \%, 39.70 \% \pm 5.90 \%$, and $49.32 \% \pm 7.62 \%$, respectively, which were also higher than that of the vehicle control group $(4.60 \% \pm 1.58 \%)$. Altogether, these results demonstrate the ability of TM208 to inhibit cell proliferation and to induce apoptosis in the MCF-7 and MDA-MB-231 cell lines.

\section{Anti-tumor effects and pharmacokinetic characteristics of} TM208 in vivo

The effects of TM208 on the in vivo growth of MCF-7 breast cancer cells in a xenograft model are shown in Figure 3. The Tam treated group was regarded as the positive control group. As shown in Figure 3A, the inhibition of tumor growth by a low TM208 dosage $\left(50 \mathrm{mg} \cdot \mathrm{kg}^{-1} \cdot \mathrm{d}^{-1}\right)$ was similar to that of Tam, and the high dosage TM208 treatment $\left(150 \mathrm{mg} \cdot \mathrm{kg}^{-1} \cdot \mathrm{d}^{-1}\right)$ caused a significant inhibition in tumor growth compared to the vehicle-treated controls and the Tam-treated group. The body weights of the TM208-treated mice were similar to those of the vehicle-treated mice (Figure 3B), indicating that TM208 inhibits the growth of MCF-7 xenograft tumors while conferring low toxicity.

The plasma concentrations of TM208 over time after treatment with $150 \mathrm{mg} \cdot \mathrm{kg}^{-1} \cdot \mathrm{d}^{-1}$ are illustrated in Figure $3 \mathrm{C}$. The major pharmacokinetic parameters were estimated from the first administration: $1.0 \pm 0.0 \mathrm{~h}\left(T_{\max }\right) ; 5056.9 \pm 2721.3 \mu \mathrm{g} \cdot \mathrm{h} / \mathrm{L}$ $\left(\mathrm{AUC}_{(0 \sim \mathrm{t})}\right) ; 4.4 \pm 0.4 \mathrm{~h}(\mathrm{MRT}) ; 39.4 \pm 28.0 \mathrm{~L} /(\mathrm{h} \mathrm{kg})(\mathrm{CL}) ; 221.4 \pm 80.9$ $\mathrm{L} / \mathrm{kg}\left(V_{\mathrm{d}}\right)$; and $4.5 \pm 1.3 \mathrm{~h}\left(\mathrm{t}_{1 / 2}\right)$. The $C_{\max }$ of the first and the last administration were $885.0 \pm 207.0$ and $1228.3 \pm 762.1 \mathrm{ng} / \mathrm{ml}$, respectively, and no significant difference was found between these groups. The detected trough concentrations of TM208 were almost unchanged during the whole period of administration. The results indicate that continuous administration did not result in the accumulation of TM208 in the tumorbearing mice.

\section{TM208 significantly inhibited the phosphorylation of EGFR and ERK1/2 in vitro and in vivo}

As shown in Figure 4A and 4B, treatment with TM208 inhibited the expression of p-EGFR and p-ERK1/2 in a dosedependent manner in both the MCF-7 and MDA-MB-231 cell lines; however, TM208 treatment did not significantly change the expression levels of total EGFR and ERK1/2. Western blot analysis showed that the phosphorylations of EGFR and ERK1/2 were also inhibited by TM208 in the tumor tissues of the MCF-7 tumor bearing nude mice (Figure 4C). The inhibitory trends of p-EGFR and p-ERK in the tumor tissues were consistent with the in vitro results, and the p-EGFR and p-ERK signals were weaker in the tumors than those in the MCF-7 and MDA-MB-231 cells.

ELISA analysis quantitatively revealed the concentrations of p-EGFR over time following a single dose or continuous administration of TM208 (Figure 4D and 4E). After a single dose of TM208, the inhibitory effect peaked at $10 \mathrm{~h}$ and then weakened gradually, but the p-EGFR concentration at $24 \mathrm{~h}$ was still lower than the initial level (Figure 4D). After continuous administration of TM208, the p-EGFR level decreased gradually over time until d 9, when the concentration stabilized. In contrast, the p-EGFR concentrations of the vehicle treatment group remained at a high level on $\mathrm{d} 0,3,6,9$, and 12, with values of $19.20 \pm 1.07,18.58 \pm 0.36,19.40 \pm 1.61,20.51 \pm 1.61$, and $20.04 \pm 0.28 \mathrm{ng} / \mathrm{mL}$, respectively (Figure $4 \mathrm{E}$ ). IHC staining showed that p-EGFR expression in the tumor tissues of the 
A

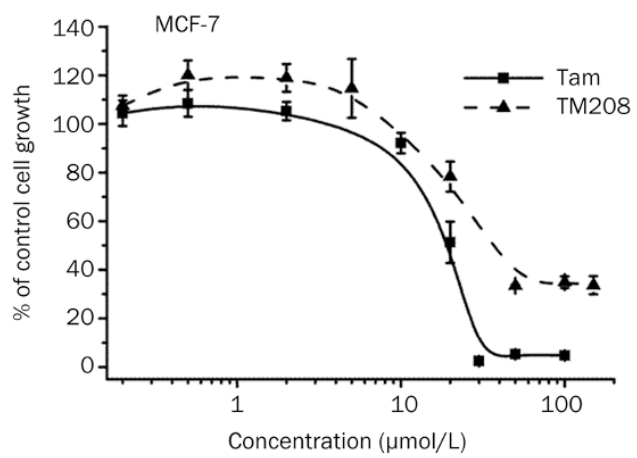

B

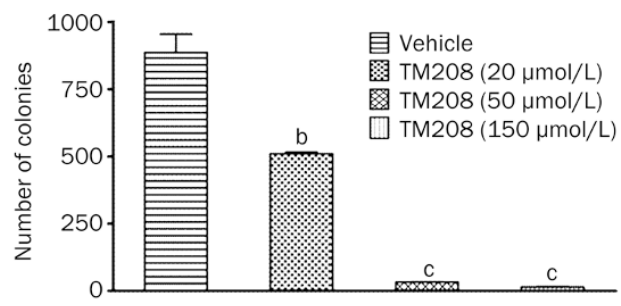

C
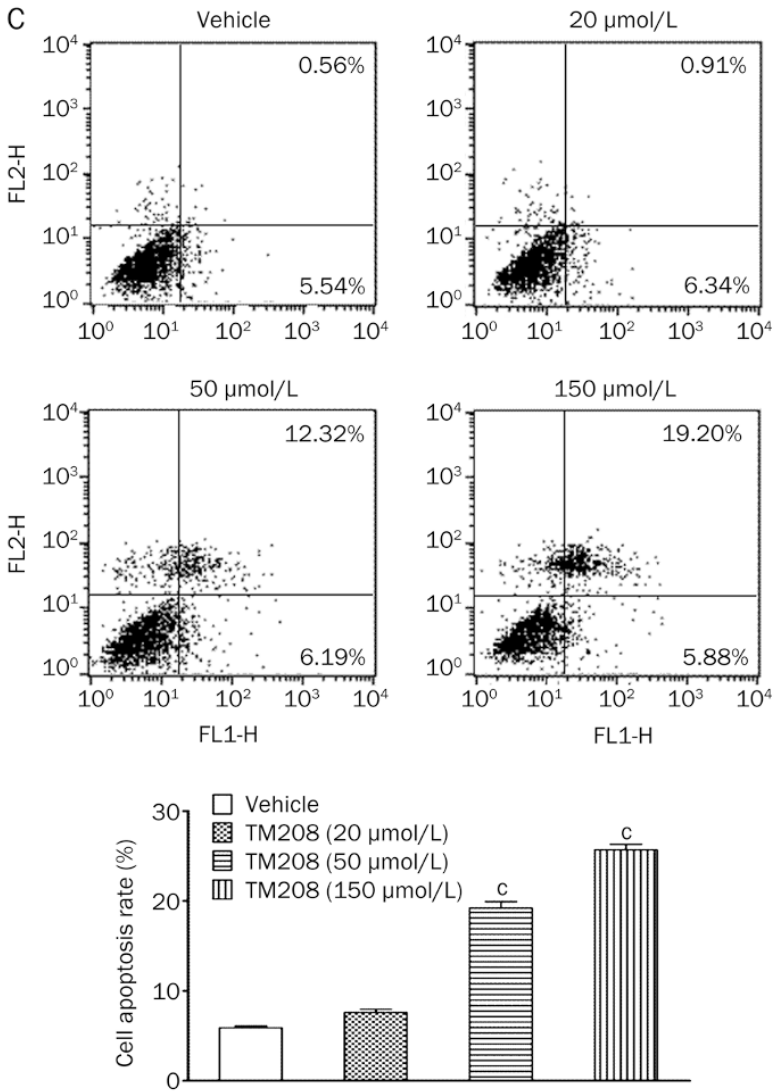
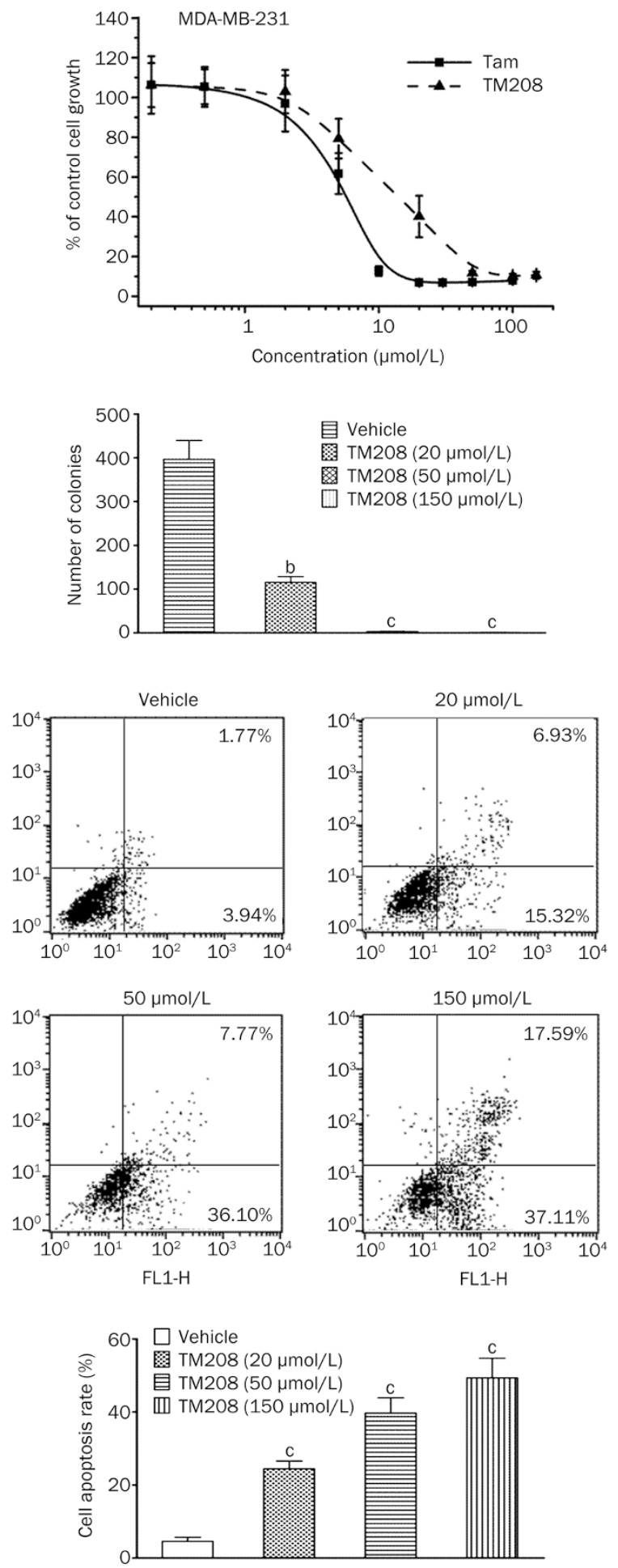

Figure 2. The effects of TM208 on the proliferation and apoptosis of breast cancer cells. (A) Cell proliferation was evaluated using the sulforhodamine B (SRB) assay. MCF-7 (left) and MDA-MB-231 (right) cells were treated with TM208 or Tam (positive control) at the indicated concentrations for $48 \mathrm{~h}$ before cell proliferation was measured. The data points are the mean \pm SD $(n=6)$. (B) Effects of TM208 on the colony formation of MCF-7 (left) and MDAMB-231 (right) cells. MCF-7 and MDA-MB-231 cells were seeded at a density of $1 \times 10^{4}$ cells per $10 \mathrm{~cm}$ dish. After treatment with TM208 at varying concentrations $(20,50$, and $150 \mu \mathrm{mol} / \mathrm{L})$ for $24 \mathrm{~h}$, the medium was replaced with fresh medium. Eight days after the initial treatment, the colonies were stained and counted. The results are presented as the mean $\pm \operatorname{SD}(n=3)$. ${ }^{\mathrm{b}} P<0.05,{ }^{\mathrm{c}} P<0.01$ vs vehicle. (C) The apoptotic percentage of TM208 in MCF-7 (left) and MDA-MB-231 (right) cells were analyzed using flow cytometry. The numbers in the respective quadrant profiles indicate the percentage of apoptotic cells. Each bar corresponds to the mean \pm SD of three independent experiments $(n=3) .{ }^{c} P<0.01$ vs vehicle. 
A

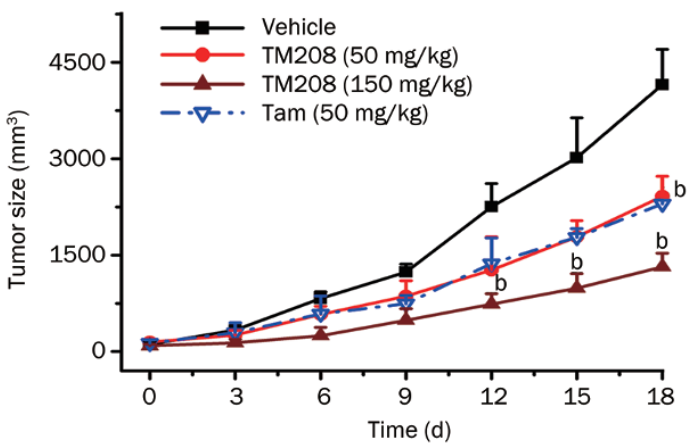

B
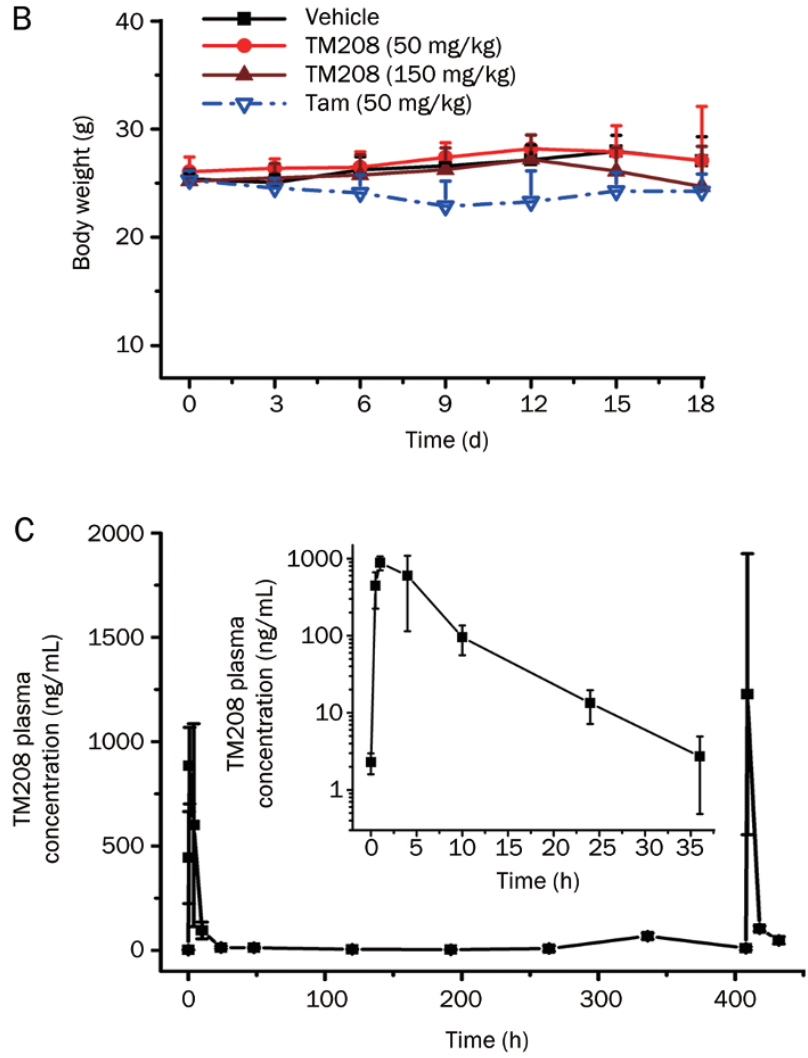

Figure 3. The effects of TM208 on the growth of MCF-7 xenograft tumors and the pharmacokinetic characteristics of TM208 in tumor-bearing mice. (A) Growth kinetics of the MCF-7 xenograft tumors in the tumorbearing mice that received the vehicle, TM208 or Tam (positive control) daily. The results are presented as the mean $\pm S D(n=4) .{ }^{b} P<0.05$ vs vehicle. (B) Body weight changes of the tumor-bearing mice that received the daily vehicle, TM208 or Tam (positive control) treatments. (C) The concentration of TM208 over time after its intragastric administration in the tumor-bearing mice at a dosage of $150 \mathrm{mg}^{-1} \mathrm{~kg}^{-1} \cdot \mathrm{d}^{-1}(n=3)$.

mice decreased in a dose-dependent manner after treatment with TM208 (Figure 4F); p-EGFR protein expression is represented by the brown staining.

\section{Discussion}

TM208 treatment inhibited the proliferation of the MCF-7 and MDA-MB-231 cell lines and remarkably suppressed the colony formation of the two breast cancer cell lines (Figure $2 \mathrm{~A}$ and $2 \mathrm{~B}$ ). The results of the apoptosis analysis indicated that TM208 induced apoptosis in a dose-dependent manner (Figure 2C). Treatment with $150 \mu \mathrm{mol} / \mathrm{L}$ TM208 resulted in $25.69 \% \pm 0.86 \%$ and $49.32 \% \pm 7.62 \%$ apoptosis in the MCF-7 cells and MDA-MB-231 cells, respectively, which were significantly higher than that of the control groups. These results suggest that the induction of apoptosis may be a result of the inhibition of p-EGFR signaling ${ }^{[3]}$, and that this inhibition plays an important role in the anti-tumor activity of TM208.

Western blot analysis showed that TM208 resulted in the remarkable reduction in both the p-EGFR and p-ERK1/2 levels in a dose-dependent manner, but the expression of total EGFR and ERK1/2 remained unchanged in each cell line (Figure 4A and 4B). Additionally, TM208 also significantly decreased the level of upstream p-EGFR protein, resulting in a maximum inhibition of approximately $50 \%$ in the tumor (Figure 4C), which was consistent with results of the immunohistochemical staining (Figure 4F). Our results indicate that TM208 exerts its effect on the topmost member of the EGFR signaling pathway, resulting in the inhibition of EGFR phosphorylation. This indicates that the other downstream signaling routes of the EGFR family, such as the PI3K/Akt pathway and the STAT pathway, may be inhibited by TM208 ${ }^{[26]}$. Moreover, EGFR is also expressed in breast cancer stem cells and even in many EGFR-negative breast tumors ${ }^{[10,11]}$, suggesting that the inhibition of EGFR signaling by TM208 may impact the growth of cancer stem cells and suppress cancer relapse.

The SRB assay showed that the $\mathrm{IC}_{50}$ values of TM208 in the MCF-7 and MDA-MB-231 cells were $36.38 \pm 3.77 \mu \mathrm{mol} / \mathrm{L}$ and $18.13 \pm 0.76 \mu \mathrm{mol} / \mathrm{L}$, respectively, suggesting that the inhibition of proliferation in the MCF-7 cells by TM208 was weaker than that of the MDA-MB-231 cells (Figure 2A). Furthermore, the TM208-mediated inhibition of colony formation and induction of apoptosis in the MDA-MB-231 cells was accordingly more significant than that in the MCF-7 cells. This may be because MCF-7 cells express low levels of EGFR, whereas EGFR is highly expressed in MDA-MB-231 cells ${ }^{[27]}$; MCF-7 cells are less sensitive to TM208 than MDA-MB-231 cells due to the inhibition of p-EGFR, and our results also show that the total EGFR protein expression in MCF-7 cells was less than that in the MDA-MB-231 cells.

Because the $\mathrm{IC}_{50}$ values of Tam were smaller than those of TM208, TM208 was weaker than Tam in inhibiting the proliferation of the two cell lines in vitro (Figure 2A). However, on d 18 of treatment with TM208 or Tam, the mean tumor volume in the mice treated with $50 \mathrm{mg} / \mathrm{kg}$ TM208 was similar to that of the Tam-treated group of the same dose (Figure 3A). This indicates that TM208 is at least comparable with Tam in exerting anti-tumor effects in MCF-7 xenograft mice. Although Tam has been used as a gold standard to antagonize the estrogen receptor in breast tissue, it has no effect on $\mathrm{p}-\mathrm{EGFR}^{[28,29]}$. Therefore, Tam was not used as a positive control in the mechanistic studies.

Cancer is a multifactorial disease, and tumor formation and progression are the results of different signaling pathways ${ }^{[30-32]}$. 
A

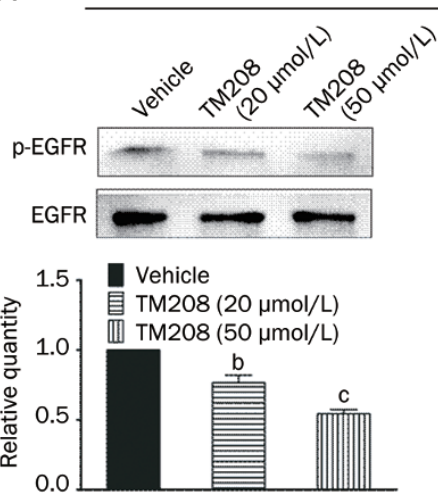

MDA-MB-231

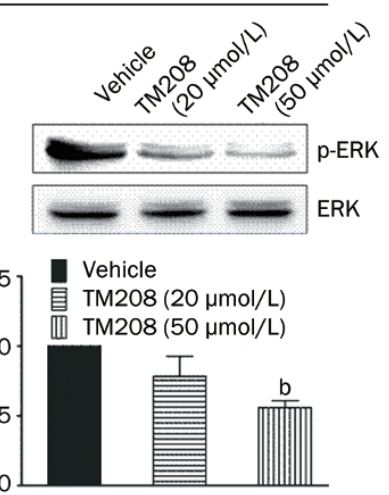

C

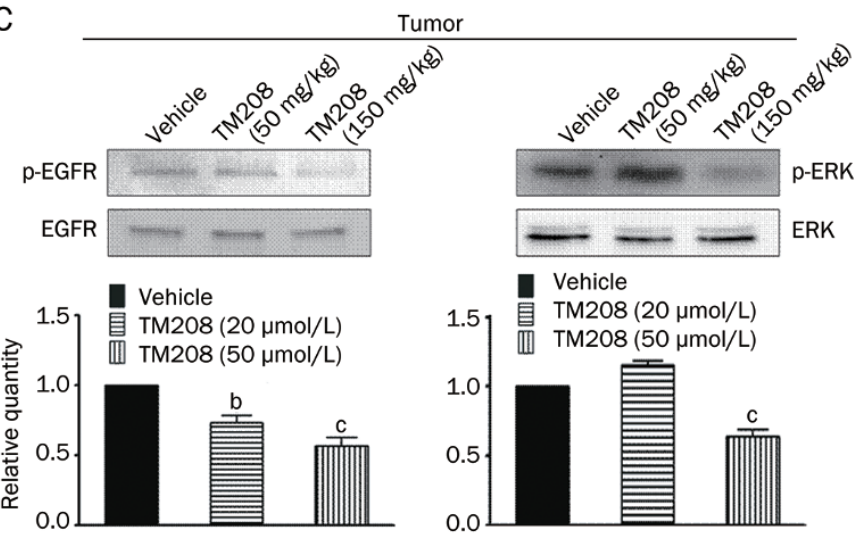

E

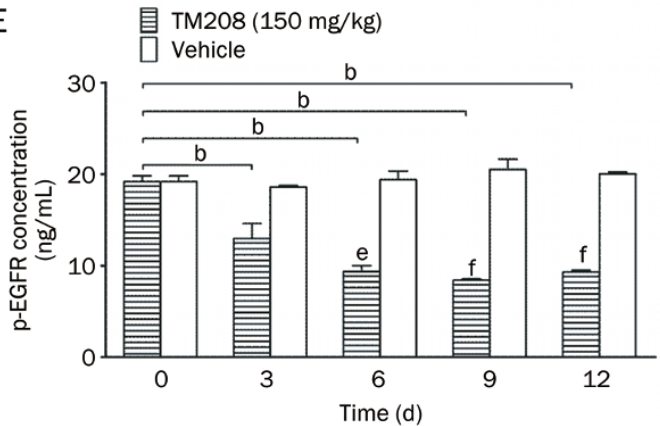

F
B

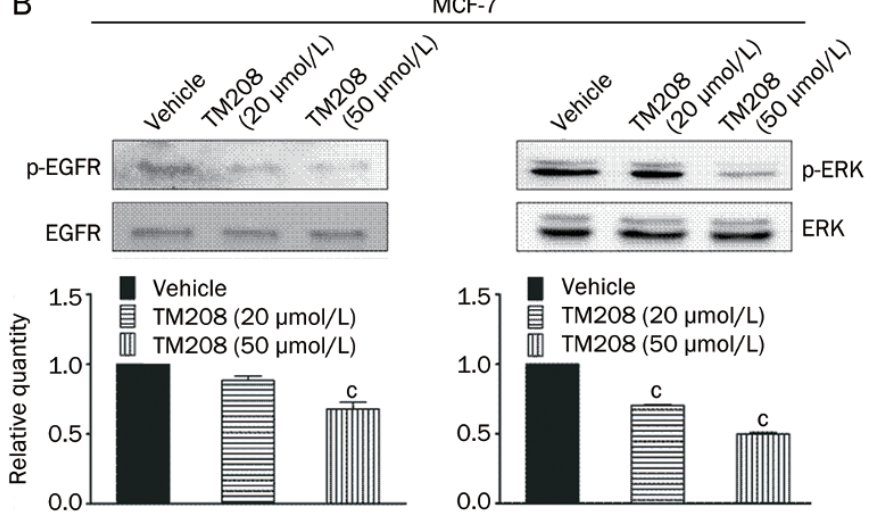

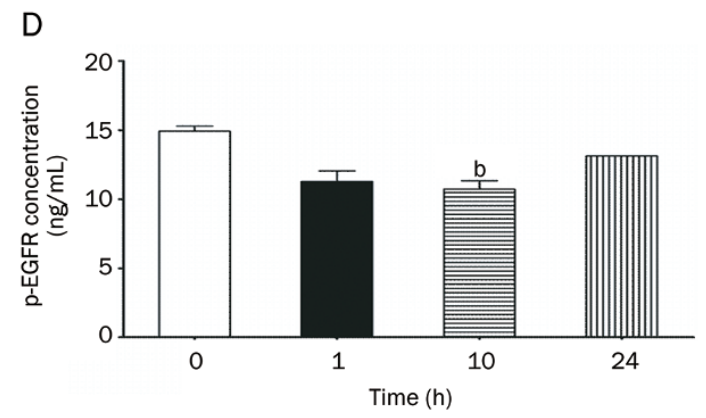
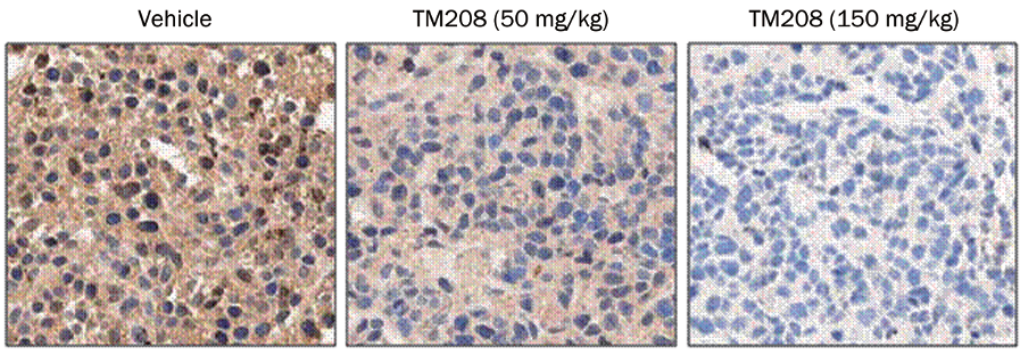

Figure 4. TM208 inhibited the phosphorylation of EGFR and ERK1/2 in vitro and in vivo. (A) TM208 reduced the expression of $p$-EGFR (left) and $p$ ERK1/2 (right) in the MDA-MB-231 cell line. (B) TM208 reduced the expression of p-EGFR (left) and p-ERK1/2 (right) in the MCF-7 cell line. (C) Western blot analysis revealed the inhibition of EGFR phosphorylation (left) and ERK1/2 phosphorylation (right) in the MCF-7 xenograft tumors treated with TM208 (50 and $150 \mathrm{mg} / \mathrm{kg}$ ). The expression levels of EGFR and ERK1/2 were included as loading controls. Each bar corresponds to the mean \pm SD of three independent experiments $(n=3)$. ${ }^{b} P<0.05,{ }^{c} P<0.01$ vs vehicle. (D) Time course analysis of $p$-EGFR concentrations in the tumors of the MCF-7 xenograft mice treated with $150 \mathrm{mg} / \mathrm{kg}$ TM208 for $24 \mathrm{~h}$. ${ }^{\mathrm{b}} \mathrm{P}<0.05 \mathrm{vs} 0 \mathrm{~h}$. (E) Time course analysis of $\mathrm{p}$-EGFR concentration in the tumors from MCF-7 xenograft mice treated with the vehicle or $150 \mathrm{mg}^{\mathrm{kg}} \mathrm{k}^{-1} \cdot \mathrm{d}^{-1} \mathrm{TM} 208$ for $12 \mathrm{~d}$. The concentrations of $\mathrm{p}$-EGFR were measured using an ELISA assay. The results are presented as the mean \pm SD $(n=3)$. ${ }^{b} P<0.05$ vs 0 d. ${ }^{e} P<0.05,{ }^{f} P<0.01$ vs vehicle. (F) $p$-EGFR immunostaining on tumor paraffin sections from mice treated with vehicle or TM208 (50 and $150 \mathrm{mg} / \mathrm{kg}$ ) for $18 \mathrm{~d}$. The original magnification is $100 \times$ for all panels.

We also found that TM208 could remarkably induce the mRNA and protein expression of estrogen sulfotransferase (EST), leading to a significant increase in its enzymatic activity in both the tumor tissue and the liver of the MCF-7 xenograft mice. Considering that excessive estrogen can be inactivated by sulfation via EST ${ }^{[33,34]}$, we anticipated that the inhibition of
p-EGFR and the induction of EST may contribute to the antibreast cancer properties of TM208, and further studies are required to determine whether there are other mechanisms, such as anti-estrogen activity, contributing to the anti-breast cancer properties of TM208.

We found that the mean p-EGFR levels in the breast tis- 
sues of the healthy nude mice were $16.44 \pm 2.00 \mathrm{ng} / \mathrm{mL}(n=3)$. However, the p-EGFR concentrations of the vehicle treated group were significantly higher than the normal level (Figure $4 \mathrm{E})$. This suggests that the p-EGFR level increases due to the status of the breast tumor, which is consistent with the previous findings ${ }^{[35]}$. In contrast, after multiple administrations of TM208, the concentrations of p-EGFR in the tumor at each time points $(0,3,6,9$, and $12 \mathrm{~d})$ were 19.20 $\pm 1.07,12.98 \pm 2.80$, $9.38 \pm 1.06,8.43 \pm 0.24$, and $9.31 \pm 0.39 \mathrm{ng} / \mathrm{mL}$ (Figure $4 \mathrm{E}$ ), during which p-EGFR level decreased approximately $10 \mathrm{ng} / \mathrm{mL}$ and stabilized on $\mathrm{d} 9$. These results suggest that continuous administration of TM208 led to a significantly lower p-EGFR concentration in the tumor compared with the pathological level. We also observed that the inhibitory effect of TM208 on p-EGFR (Figure 4D) after a single-dose lagged behind the plasma concentration of TM208 (Figure 3C), demonstrating the duration of time involved in the transduction of the TKs ${ }^{[7,8]}$.

In summary, this is a study of the anti-breast cancer effects of TM208 and its mechanism of action. Our studies demonstrate that inhibiting the autophosphorylation of EGFR plays an important role in the anti-breast cancer efficacy of TM208 and other dithiocarbamates. Furthermore, we investigated the pharmacokinetic characteristics of TM208 in the tumor xenograft model, which should be helpful in establishing a pharmacokinetic/pharmacodynamic link model to describe the quantitative relationship between the drug concentration and tumor size in the near future.

\section{Acknowledgements}

This work was supported by the National Natural Science Foundation of China (NSFC) [Grant 81273583].

\section{Author contribution}

Wei LU and Tian-yan ZHOU designed the research; Xi-wei JI, Xue-yan SHAO, Si-yuan WANG and Yin YUAN performed the research; Run-tao LI and Zai-quan LI contributed new reagents or analytic tools; Xi-wei JI and Liang LI analyzed the data; Xi-wei JI wrote the paper.

\section{Abbreviations}

TM208, 4-methyl-piperazine-1-carbodithioc acid 3-cyano-3, 3-diphenylpropyl ester hydrochloride; Tam, tamoxifen; TK, tyrosine kinase; EGFR, epidermal growth factor receptor; p-EGFR, phosphorylated EGFR; ERK, extracellular signalregulated kinase; p-ERK, phosphorylated ERK.

\section{References}

1 Al Olayan A, Al Hussaini H, Jazieh AR. The roles of epidermal growth factor receptor (EGFR) inhibitors in the management of lung cancer. J Infect Public Health 2012; 5: S50-60.

2 Murray S, Dahabreh IJ, Linardou H, Manoloukos M, Bafaloukos D, Kosmidis P. Somatic mutations of the tyrosine kinase domain of epidermal growth factor receptor and tyrosine kinase inhibitor response to TKIs in non-small cell lung cancer: an analytical database. J Thorac Oncol 2008; 3: 832-9.

3 Woodburn JR. The epidermal growth factor receptor and its inhibition in cancer therapy. Pharmacol Ther 1999; 82: 241-50.
4 Nicholson RI, Gee JM, Harper ME. EGFR and cancer prognosis. Eur J Cancer 2001; 37: 9-15.

5 Abd El-Rehim DM, Pinder SE, Paish CE, Bell JA, Rampaul RS, Blamey RW, et al. Expression and co-expression of the members of the epidermal growth factor receptor (EGFR) family in invasive breast carcinoma. Br J Cancer 2004; 91: 1532-42.

6 Salomon DS, Brandt R, Ciardiello F, Normanno N. Epidermal growth factor-related peptides and their receptors in human malignancies. Crit Rev Oncol Hematol 1995; 19: 183-232.

7 Liebmann C. Regulation of MAP kinase activity by peptide receptor signalling pathway: paradigms of multiplicity. Cell Signal 2001; 13: 777-85.

8 Hill CS, Treisman R. Transcriptional regulation by extracellular signals: mechanisms and specificity. Cell 1995; 80: 199-211.

9 Garrett JT, Sutton CR, Kuba MG, Cook RS, Arteaga CL. Dual blockade of HER2 in HER2-overexpressing tumor cells does not completely eliminate HER3 function. Clin Cancer Res 2013; 19: 610-9.

10 Farnie G, Clarke RB, Spence K, Pinnock N, Brennan K, Anderson NG, et al. Novel cell culture technique for primary ductal carcinoma in situ: role of Notch and epidermal growth factor receptor signaling pathways. J Natl Cancer Inst 2007; 99: 616-27.

11 Li X, Lewis MT, Huang J, Gutierrez C, Osborne CK, Wu MF, et al. Intrinsic resistance of tumorigenic breast cancer cells to chemotherapy. J Natl Cancer Inst 2008; 100: 672-9.

12 Len C, Boulognemerlot AS, Postel D. Synthesis and antifungal activity of novel bis(dithiocarbamate) derivatives of glycerol. J Agric Food Chem 1996; 44: 2856-8.

13 Cascio G, Lorenzi L, Caglio D, Manghisi E, Arcamone F, Guanti G, et al. Synthesis and antibacterial activity of C-4 thio-and dithiocarbamate monobactam derivatives. Farmaco 1996; 51: 189-96.

14 Lai CS. Preparation of conjugates of dithiocarbamates with drugs. P. PCT Int. Appl, WO 9855453 A1, 1998-12-10 (66).

15 Hidaka S, Funakoshi T, Shimada H, Tsuruoka M, Kojima S. Comparative effects of diethyldithiocarbamate and N-benzyl-D-glucamine dithiocarbamate on cis-diamminedichloroplatinum-induced toxicity in kidney and gastrointestinal tract in rats. J Appli Toxicol 1995; 15: 267-73.

16 Guo BG, Ge ZM, Cheng TM. Synthesis and anti-tumor activity of 1,4-bis[3-(aminodithiocarboxyl) propionyl] pipera-zine derivatives. Acta Pharm Sinica 2001; 36: 185-7.

17 Ge ZM, Li RT, Cheng TM, Cui JR. Synthesis and biological activities of dipiperazinium salts containing dithiocarboxyl. Arch Pharm Pharm Med Chem 2001; 334: 173-6.

18 Li RT, Cheng TM, Cui JR. Study on the synthesis and anticancer activity of dithiocarbamate. US patent: 1328999, 2002-01.

19 Li RT, Cheng TM, Cui JR. Piperazine mono(dithio)-carbamate ester compounds and analog: preparation method and pharmaceutical use. US patent: 10/157733, 2002-05; WO Apply No: PCT/US02/16772, 2002-5.

20 Li RD, Zhang X, Li QY, Ge ZM, Li RT. Novel EGFR inhibitors prepared by combination of dithiocarbamic acidesters and 4-anilinoquinazolines. Bioorg Med Chem Lett 2011; 21: 3637-40.

21 Guo W, Rang FX, Wang RQ, Cui JR, Li RT, Cheng TM, et al. Antitumor effect of hydrochloride 4-methyl-piperazine-1-carbodithioc acid 3-cyano-3,3-diphenyl-propyl ester. Chin J Clin Pharmacol Ther 2004; 9: 59-62.

22 Zhang N, Guo W, Wang L, Huang W, Xu B, Ge ZM, et al. Effect of TM208 on QGY-7703 xenograft tumor growth. Anticancer Drugs 2008; 19: 593-8.

23 Jiang X, Ling X, Han F, Li R, Cui J. Studies on the metabolism of 4-methyl-piperazine-1-carbodithioc acid 3-cyano-3,3-diphenylpropyl 
ester hydrochloride in rats by high-performance liquid chromatography/electrospray ionization tandem mass spectrometry. J Pharm Biomed Anal 2007; 44: 1127-32.

24 Kakuta Y, Pedersen LC, Chae K, Song WC, Leblanc D, London R, et al. Mouse steroid sulfotransferases: substrate specificity and preliminary X-ray crystallographic analysis. Biochem Pharmacol 1998; 55: 313-7.

25 Ji X, Chen Y, Li R, Zhou T, Lu W. A high-sensitivity LC-MS/MS method for the determination of 4-methyl-piperazine-1-carbodithioc acid 3-cyano-3, 3-diphenylpropyl ester hydrochloride in rat plasma and its application to a pharmacokinetics study. Biomed Chromatogr 2012; 26: 1196-201.

26 Lurje G, Lenz HJ. EGFR signaling and drug discovery. Oncology 2009; 77: 400-10.

27 Mamot C, Drummond DC, Greiser U, Hong K, Kirpotin DB, Marks $J D$, et al. Epidermal Growth Factor Receptor (EGFR)-targeted Immunoliposomes Mediate Specific and Efficient Drug Delivery to EGFR- and EGFRvlll-overexpressing Tumor Cells. Cancer Res 2003; 63: 3154-61.

28 Jordan VC. Tamoxifen $(\mathrm{ICl} 46,474)$ as a targeted therapy to treat and prevent breast cancer. Br J Pharmacol 2006; 147: 269-76.

29 Jordan VC, Morrow M. Tamoxifen, raloxifene, and the prevention of breast cancer. Endocr Rev 1999; 20: 253-78.

30 Brinkman JA, El-Ashry D. ER re-expression and re-sensitization to endocrine therapies in ER-negative breast cancers. J Mammary Gland Biol Neoplasia 2009; 14: 67-78.

31 Zhou J, Yu Q, Chen R, Seeger H, Fehm T, Cahill MA, et al. Medroxyprogesterone acetate-driven increase in breast cancer risk might be mediated via cross-talk with growth factors in the presence of progesterone receptor membrane component-1. Maturitas 2013; 76 : 129-33.

32 Bayliss J, Hilger A, Vishnu P, Diehl K, El-Ashry D. Reversal of the estrogen receptor negative phenotype in breast cancer and restoration of antiestrogen response. Clin Cancer Res 2007; 13: 7029-36.

$33 \mathrm{Xu}$ Y, Liu X, Guo F, Ning Y, Zhi X, Wang X, et al. Effect of estrogen sulfation by SULT1E1 and PAPSS on the development of estrogendependent cancers. Cancer Sci 2012; 103: 1000-9.

34 Gong H, Jarzynka MJ, Cole TJ, Lee JH, Wada T, Zhang B, et al. Glucocorticoids antagonize estrogens by glucocorticoid receptormediated activation of estrogen sulfotransferase. Cancer Res 2008; 68: 7386-93.

35 Magkou C, Nakopoulou L, Zoubouli C, Karali K, Theohari I, Bakarakos $\mathrm{P}$, et al. Expression of the epidermal growth factor receptor (EGFR) and the phosphorylated EGFR in invasive breast carcinomas. Breast Cancer Res 2008; 10: R49. 